\title{
Growth temperature ranges of Borrelia burgdorferi sensu lato strains
}

\author{
Z. HUBÁLEK, J. HALOUZKA and M. HEROLDOVÁ* \\ Institute of Landscape Ecology, Academy of Sciences, Kvetná 8, CZ-60365 Brno and * Department of \\ Microbiology, Faculty of Science, Masaryk University, Brno, Czech Republic
}

\begin{abstract}
Three strains of Borrelia burgdorferi sensu lato, representing three human pathogenic genomospecies (B31, B. burgdorferi sensu stricto; BR14, B. garinii; BR75, B. afzelii) were grown in BSK-H medium at different temperatures and the spirochaetal cells were counted by dark-field microscopy after $0,4,8,16$ and 48 days. Approximate optimum (minimum-maximum) temperatures for the in-vitro growth were found to be $33^{\circ} \mathrm{C}(22-$ $\left.39^{\circ} \mathrm{C}\right)$ in strain $B 31,35^{\circ} \mathrm{C}\left(20-40^{\circ} \mathrm{C}\right)$ in strain $\mathrm{BR} 75$ and $37^{\circ} \mathrm{C}\left(20-41^{\circ} \mathrm{C}\right)$ in strain BR14. Maximum, optimum and minimum growth temperatures seem to be important characteristics of $B$. burgdorferi s.l. strains, with relevance for the symptomatology, epidemiology and epizoology of Lyme borreliosis.
\end{abstract}

\section{Introduction}

Borrelia burgdorferi sensu lato (s.1.), the causative agent of Lyme borreliosis, is a tick-borne spirochaete 'shuttling' principally between the vector tick and a homeotherm vertebrate host. This life cycle requires the bacterium to be able to replicate (or at least survive for a long time) in three or four very different environments and temperatures: (i) unfed tick (at ambient temperature); (ii) blood-sucking tick (c. 30$35^{\circ} \mathrm{C}$ ) and (iii) homeotherm vertebrate (mammalian or avian) tissue, either on the skin $\left(32-37^{\circ} \mathrm{C}\right)$ or in internal organs $\left(37-41^{\circ} \mathrm{C}\right)$. However, information on temperature requirements of $B$. burgdorferi s.l. is limited. The optimum temperature for its growth in vitro has been given widely as $30-37^{\circ} \mathrm{C}$ [1]. The spirochaete is usually grown in BSK-II (or BSK-H, Sigma) medium at $32-34^{\circ} \mathrm{C}$ (most often at $33^{\circ} \mathrm{C}$ ), but sometimes at $30-31^{\circ} \mathrm{C}$ or $35^{\circ} \mathrm{C}$. Nevertheless, no exact studies on the optimum temperature for the growth of B. burgdorferi s.l. strains have been published. As yet, even less is known about the range of temperatures for the growth of $B$. burgdorferi s.l. The maximum temperature for multiplication of $B$. burgdorferi sensu stricto (s.s.) and B. afzelii (strain PKo) was reported to be $39^{\circ} \mathrm{C}$, while no growth was observed at temperatures of $\geqslant 40^{\circ} \mathrm{C}[1,2]$. These observations contradict some reported isolations of $B$. burgdorferi s.s. from birds that have normal body temperature of $c .41^{\circ} \mathrm{C}$, e.g., from the liver of a veery (Catharus fuscescens) [3], the

Received 8 July 1997; revised version accepted 19 Jan. 1998.

Corresponding author: Dr Z. Hubálek. blood of a song sparrow (Melospiza media) [4] and the blood and internal organs of experimentally inoculated mallard ducks (Anas platyrhynchos) [5] and canary finches (Serinus canaria) [6]. The isolate from the veery liver (VL) was also recovered from chicks inoculated experimentally [3]. Moreover, B. garinii was re-isolated from the skin and several organs of Japanese quails (Coturnix japonica) between 7 and 56 days after inoculation [7]. Only one strain of $B$. burgdorferi (ATCC 35211, isolated from Ixodes ricinus in Switzerland) was found to survive at $41^{\circ} \mathrm{C}$ in vitro for up to 4 days [2]. In contrast, there are no reports about the growth parameters of B. burgdorferi s.l. at ecologically meaningful temperatures $<30^{\circ} \mathrm{C}$ which prevail in vector ticks during their non-parasitic stage of life cycle; only one recent paper has mentioned a slow in-vitro growth of $B$. burgdorferi at $23^{\circ} \mathrm{C}$ [8]. The present study investigated the maximum, minimum and optimum growth temperatures for selected strains of $B$. burgdorferi, B. garinii and B. afzelii.

\section{Materials and methods}

Three strains of $B$. burgdorferi s.l., representing the three known human pathogenic genomic groups ('genomospecies' or 'genospecies'), were tested: (1) type strain B31 (ATCC 35210) of B. burgdorferi s.s., isolated from Ixodes scapularis collected on Shelter Island, NY and passaged $>20$ times in vitro, including eight passages in this laboratory at $33^{\circ} \mathrm{C}$; (2) strain BR14 (B. garinii), isolated from nymphal Ixodes ricinus collected in South Moravia, Czech Republic and passaged 11 times in vitro at $33^{\circ} \mathrm{C}$ [9]; and (3) 
strain BR75 (B. afzelii), isolated from Ctenophthalmus agyrtes fleas collected on Clethrionomys glareolus in South Moravia and passaged nine times in vitro at $33^{\circ} \mathrm{C}$ [9]. The spirochaetes were grown at $33^{\circ} \mathrm{C}$ in BSK-H medium (Sigma) supplemented with rabbit serum (Sigma) $5 \%$, phosphomycin $100 \mu \mathrm{g} / \mathrm{ml}$ and rifampicin $50 \mu \mathrm{g} / \mathrm{ml}$. About $1 \times 10^{5}$ cells from the logarithmic phase of growth (4-5-day-old cultures, with a cell motility of $90-99 \%$ and a cell density of $\left.(5-10) \times 10^{7} / \mathrm{ml}\right)$ were inoculated into 4-ml glass tubes containing $3.5 \mathrm{ml}$ of BSK-H medium with rabbit serum $5 \%$ and antibiotics, tightly stoppered and incubated for up to 48 days at various temperatures as follows (their ecological relevance is given in parentheses): $20^{\circ} \mathrm{C}$ (mean daily air temperature in July, Central Europe); $28^{\circ} \mathrm{C}$ (maximum daily air temperature in summer, Central Europe); $33^{\circ} \mathrm{C}$ (approximate skin temperature of mammals); $37^{\circ} \mathrm{C}$ (average body temperature of mammals and approximate skin temperature of birds) and $41^{\circ} \mathrm{C}$ (average body temperature of birds). The temperature of incubators was checked continuously by thermometers placed at the level of culture racks; the temperature fluctuation did not exceed $\pm 0.2^{\circ} \mathrm{C}$ in any of the incubators used. For each of the three strains, tubes were incubated for $4,8,16$ and 48 days at each of the five temperatures (60 tubes in total). The number of organisms present was determined by dark-field microscopy of $10-\mu \mathrm{l}$ volumes, after appropriate dilution and in triplicate by two observers, at time 0 , and after each incubation period at each temperature. The cell density was calculated as the mean number of spirochaetes (motile plus non-motile) per ml. Motility rate (percentage of total number of spirochaetes) was evaluated separately in undiluted samples by inspecting at least 100 spirochaetes and taken as an indication of viability. Statistical analyses (ANOVA, $t$ test) were performed with the SOLO package (BMDP Statistical Software, Los Angeles, CA, USA).

\section{Results}

The log numbers and motility rates of borreliae at different temperatures and intervals are shown in Fig. 1. All three strains grew at $28-37^{\circ} \mathrm{C}$, and the number of spirochaetes increased by $2-3 \log _{10}$ during the cultivation period. Only strain BR 14 multiplied at $41^{\circ} \mathrm{C}$ : $63 \%$ of the spirochaetes were still motile after 8 days, and $1 \%$ remained motile until the 16 th day. Strains BR14 and BR75 both multiplied well, although slowly, at $20^{\circ} \mathrm{C}$. The optimum temperature, i.e., that giving the highest growth rate, was found to be $33^{\circ} \mathrm{C}$ for strain $\mathrm{B} 31,33-37^{\circ} \mathrm{C}$ for $\mathrm{BR} 75$ and $37^{\circ} \mathrm{C}$ for BR14. Maximum cell density values were reached in all three strains at $33^{\circ} \mathrm{C}$. After attaining the maximum cell density of $c$. $(1-10) \times 10^{7} / \mathrm{ml}$, the motility rate of the spirochaetes generally decreased quite rapidly at all permissive temperatures. Strains BR14 and BR75 remained motile for $>48$ days at the lowest temperatures of $20-28^{\circ} \mathrm{C}$ and $20^{\circ} \mathrm{C}$, respectively.
Statistical analysis demonstrated significant effects $(p<0.0001)$ of the strain, temperature and time period on the number of borrelial cells. The spirochaetal numbers among all 63 cultures (i.e., three strains $\times$ five temperatures $\times$ four time periods plus all three strains at time 0 ) were compared by the $t$ test. Of the 2775 pair-wise comparisons, the differences were significant $(\mathrm{p}<0.05)$ in $2333(84.1 \%)$. In general, all histogram differences $>0.3 \log$ were revealed as significant $(\mathrm{p}<0.05)$ (Fig. 1). For instance, at $33^{\circ} \mathrm{C}$, the numbers of cells in the strain B31 culture decreased significantly between days 8 and 16 , and 16 and 48, while those in strain BR75 decreased significantly only between days 16 and 48 , but not between days 8 and 16 .

In separate tests, no growth or motility of any strain was observed after 4 days at $42.0^{\circ} \mathrm{C}$. Spirochaetes of strains BR14 and BR75 (but not B31) multiplied 4050 times in 8 days at $40.2^{\circ} \mathrm{C}$; the motility rate after 8 days was $2 \%$ in strain BR75 and $6 \%$ in strain BR 14 . Strain B31 multiplied at $39^{\circ} \mathrm{C}, 25^{\circ} \mathrm{C}$ (well) and $22^{\circ} \mathrm{C}$. One culture of each strain was tested after prolonged incubation for 81 days at $20^{\circ} \mathrm{C}$; the mean cell numbers $/ \mathrm{ml}$ (and motility rates) in strains B31, BR14 and BR75 were $0(0 \%), 6.2878 \times 10^{7}(98 \%)$ and $3.7333 \times 10^{7}(74 \%)$, respectively.

\section{Discussion}

Different temperature requirements for the growth of three strains of $B$. burgdorferi s.l., representing the three known human pathogenic genomic groups, were detected. Approximate optimum (and minimum to maximum) temperatures were $33^{\circ} \mathrm{C}\left(22-39^{\circ} \mathrm{C}\right)$ for strain B31 (B. burgdorferi s.s.), $35^{\circ} \mathrm{C}\left(20-40^{\circ} \mathrm{C}\right)$ for strain BR75 (B. afzelii) and $37^{\circ} \mathrm{C}\left(20-41^{\circ} \mathrm{C}\right)$ for strain BR14 (B. garinii). Although only one strain of each genomic group was used, and strain variability in temperature requirements within each group might exist, the present data indicate that $B$. garinii is the most thermotolerant and $B$. burgdorferi the least thermotolerant genomic group among human pathogenic $B$. burgdorferi s.l.. The $1-2^{\circ} \mathrm{C}$ difference in optimum and maximum temperatures between $B$. afzelii and B. garinii could explain in part the observed difference in clinical symptomatology caused by these genomospecies: whereas $B$. afzelii usually predominates in skin manifestations (erythema migrans, acrodermatitis chronica atrophicans), B. garinii is relatively more frequently associated with internal forms like neuroborreliosis (e.g., meningoradiculoneuritis) [10].

The normal rectal temperature of birds is $c .41^{\circ} \mathrm{C}$, slightly varying among species (e.g., $40.1-42.1^{\circ} \mathrm{C}$ in chicken, $40.9^{\circ} \mathrm{C}$ in turkey, $41.1^{\circ} \mathrm{C}$ in duck, $40.6^{\circ} \mathrm{C}$ in goose, $40.6-41.9^{\circ} \mathrm{C}$ in pigeon), but reaching up to $44^{\circ} \mathrm{C}$ during intense activity [11]. Borrelial strains which do not grow at $41^{\circ} \mathrm{C}$ in vitro obviously cannot 

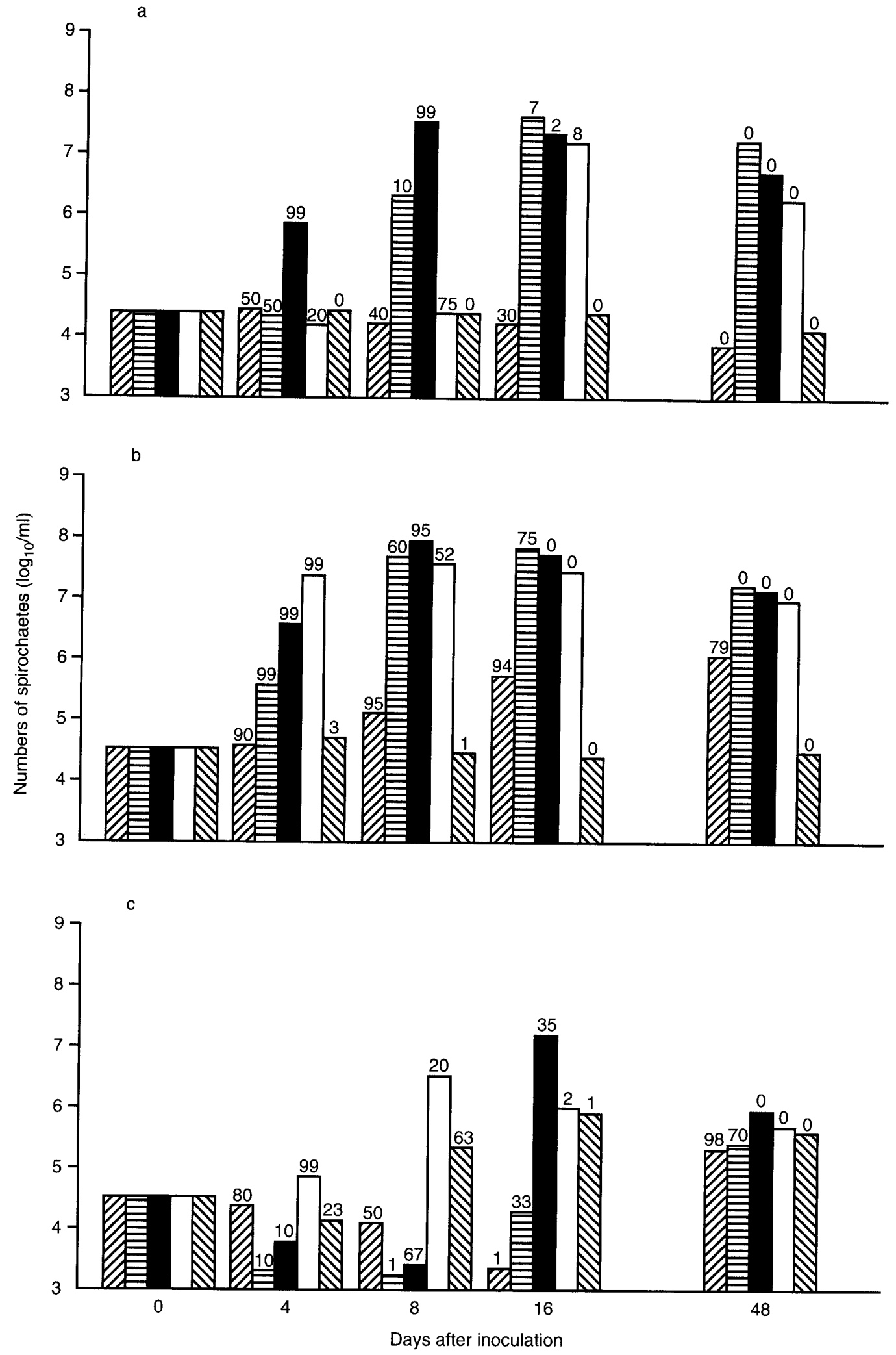

Fig. 1. The growth rate of strains $\mathrm{B} 31$ (B. burgdorferi sensu stricto, a), BR75 (B. afzelii, b) and BR14 (B. garinii, c) at various temperatures: $2,20^{\circ} \mathrm{C} ;\left[, 28^{\circ} \mathrm{C} ; \mathbf{\square}, 33^{\circ} \mathrm{C} ; \square, 37^{\circ} \mathrm{C} ; 41^{\circ} \mathrm{C}\right.$. The figures above histograms show the motility rate $(\%)$ of the spirochaetes.

replicate in avian bodies. Birds are therefore probably incompetent as long-term hosts for $B$. burgdorferi. However, some avian species might be able to amplify $B$. burgdorferi s.l. because the spirochaetes have been isolated from them under natural $[3,4]$ or experi- mental [5-7] conditions. In addition, a higher prevalence $(21.4 \%)$ of the spirochaetes was detected in larval Ixodes scapularis ticks parasitising veeries (Catharus fuscescens) than other avian species (usually $<10 \%)$ in north-eastern USA [12]. This indicates 
that some of the veeries carried the spirochaetes in their skin tissue or blood. Isolations of $B$. burgdorferi s.s. from birds probably reflect strain variability in maximum temperature for growth within this genomospecies; there must be some strains that tolerate a temperature of $41^{\circ} \mathrm{C}$. B. garinii, the genomospecies with the highest maximum growth temperature as found in this study, has been detected in, or isolated from, ixodid ticks parasitising Eurasian birds significantly more often than the other Borrelia genomospecies [13-16]. In contrast, $B$. afzelii has been isolated more frequently from small mammals than from birds [9, 15]. In addition, the results of the present study also show the potential of $B$. burgdorferi s.l. spirochaetes to multiply in unfed vector ticks during summer temperatures of the north temperate (mid-latitude) zone. The maximum and minimum temperatures for growth thus seem to be phenotypic characters important in the ecology of $B$. burdorferi s.1. strains, with relevance for the symptomatology, epidemiology and epizootiology of Lyme borreliosis. Moreover, the temperature shift from ambient temperature in the vector tick to the higher temperature of an endothermic vertebrate host (and vice versa) has significant implications for differential expression of outer surface [8] or heat-shock [17] proteins by $B$. burgdorferi s.l. This antigenic or protein 'dimorphism' of the agent could greatly affect the immune response of the vertebrate host as well as the pathogenesis of Lyme borreliosis.

We are very grateful to Dr J. F. Anderson who provided the type strain of $B$. burgdorferi and to Dr D. Postic for the identification of strains BR14 and BR75. This study was funded by the Grant Agency of the Academy of Sciences of the Czech Republic (A6087601).

\section{References}

1. Barbour AG. Isolation and cultivation of Lyme disease spirochetes. Yale J Biol Med 1984; 57: 521-525.

2. Reisinger E, Wendelin I, Gasser R, Halwachs G, Wilders-
Truschnig M, Krejs G. Antibiotics and increased temperature against Borrelia burgdorferi in vitro. Scand J Infect Dis 1996; 28: $155-157$.

3. Anderson JF, Johnson RC, Magnarelli LA, Hyde FW. Involvement of birds in the epidemiology of the Lyme disease agent Borrelia burgdorferi. Infect Immun 1986; 51: 394-396.

4. McLean RG, Ubico SR, Hughes CAN, Engstrom SM, Johnson $\mathrm{RC}$. Isolation and characterization of Borrelia burgdorferi from blood of a bird captured in the Saint Croix River Valley. J Clin Microbiol 1993; 31: 2038-2043.

5. Burgess EC. Experimental inoculation of mallard ducks (Anas platyrhynchos platyrhynchos) with Borrelia burgdorferi. $J$ Wildl Dis 1989; 25: 99-102.

6. Olsén B, Gylfe A, Bergström S. Canary finches (Serinus canaria) as an avian infection model for Lyme borreliosis. Microb Pathog 1996; 20: 319-324.

7. Isogai E, Tanaka S, Braga IS et al. Experimental Borrelia garinii infection of Japanese quail. Infect Immun 1994; 62: $3580-3582$

8. Stevenson B, Schwan TG, Rosa PA. Temperature-related differential expression of antigens in the Lyme disease spirochete, Borrelia burgdorferi. Infect Immun 1995; 63: 4535-4539.

9. Hubálek Z, Halouzka J, Juřicová Z. Investigation of haematophagous arthropods for borreliae - summarized data, 19881996. Folia Parasitol 1998; 45: 67-72.

10. van Dam AP, Kuiper H, Vos K et al. Different genospecies of Borrelia burgdorferi are associated with distinct clinical manifestations of Lyme borreliosis. Clin Infect Dis 1993; 17: $708-717$

11. Richter W, Werner E, Bähr H. Grundwerte der Tiergesundheit und Tierhaltung. VEB G. Fischer, Jena, 1979.

12. Magnarelli LA, Stafford KC, Bladen VC. Borrelia burgdorferi in Ixodes dammini (Acari: Ixodidae) feeding on birds in Lyme, Connecticut, U.S.A. Can J Zool 1992; 70: 2322-2325.

13. Bunikis J, Olsén B, Fingerle B, Bonnedahl J, Wilske B, Bergström S. Molecular polymorphism of the Lyme disease agent Borrelia garinii in Northern Europe is influenced by a novel enzootic Borrelia focus in the North Atlantic. $J$ Clin Microbiol 1996; 34: 364-368.

14. Hubálek Z, Anderson JF, Halouzka J, Hájek V. Borreliae in immature Ixodes ricinus (Acari: Ixodidae) ticks parasitizing birds in the Czech Republic. J Med Entomol 1996; 33: 766-771.

15. Nakao M, Miyamoto M, Fukunaga M. Lyme disease spirochetes in Japan: enzootic transmission cycles in birds, rodents, and lxodes persulcatus ticks. $J$ Infect Dis 1994; 170: 878-882.

16. Olsén B, Jaenson TGT, Bergström S. Prevalence of Borrelia burgdorferi sensu lato-infected ticks on migrating birds. Appl Environ Microbiol 1995; 61: 3082-3087.

17. Cluss RG, Goel AS, Rehm HL, Schoenecker JG, Boothby JT. Coordinate synthesis and turnover of heat shock proteins in Borrelia burgdorferi: degradation of DnaK during recovery from heat shock. Infect Immun 1996; 64: 1736-1743. 